\title{
Some factors affecting the incubation period and duration of symptoms of urethritis in men
}

\author{
C B S SCHOFIELD \\ From Ward 34, Newcastle General Hospital, Newcastle upon Tyne
}

SUMMARY In a retrospective study of clinic records containing accurate information on the dates of infection and onset of symptoms, the mean ( \pm SEM) incubation period of gonorrhoea in men was $6 \cdot 2 \pm 3 \cdot 8$ days and the mean duration of symptoms $3 \cdot 1 \pm 2 \cdot 3$ days. For non-specific urethritis the mean ( \pm SEM) figures were $7 \cdot 7 \pm 4 \cdot 1$ and $4 \cdot 0 \pm 3 \cdot 4$ days respectively; both were significantly longer than for gonorrhoea.

Patients with a first episode of urethritis had longer than average incubation periods and $\vec{\infty}$ duration of symptoms. Past experience of urethritis shortened the duration of symptoms; this was more significant in gonorrhoea than in non-specific urethritis. "Anxious" men who had attended previously of their own accord when no abnormality had been found had the shortest times. The most notable factor in determining the interval between infection and attendance, however, was whether or not the sexual contact was known. Infections by known contacts were associated with prolonged duration of symptoms which negated the benefit of past experience and, to some extent, of anxiety.

Thus, patients should be made more generally aware that known contacts may be a source of infection, especially after a break in a relationship, and that they should return to the clinic as soon as symptoms develop. Furthermore, doctors should examine carefully even the most persistently "neurotic" patients, because they may eventually become infected.

\section{Introduction}

The incubation period of urethral gonorrhoea in men is variously quoted as being from one to 10 days (but mostly five days or less) by King et al, ${ }^{1}$ from two to five days by Catterall ${ }^{2}$ and Morton ${ }^{3}-$ who notes that some authorities mention an extreme of 2-3 weeks $s^{3}$-from three to five days by Robertson et $a l^{4}{ }^{4}$ and an average of $7 \cdot 9$ days. 5

The incubation period of non-specific urethritis (NSU) is even less precise: from five to 28 days, ${ }^{2}$ from one to three weeks, ${ }^{1}$ from one to four weeks, ${ }^{5}$ from a few days to a few weeks, ${ }^{4}$ and, for half the patients, over 10 days. ${ }^{3}$

The duration of symptoms before patients attend for treatment is ignored by all except one author, who quotes a mean period of $4 \cdot 5$ days for gonorrhoea ${ }^{s}$ but does not mention that for NSU. It is unfortunate that little interest is paid to this period during which the patients are symptomatic and

Address for reprints: Dr C B S Schofield. Ward 34. Newcastle General Hospital, Westgate Road. Newcastle upon Tyine NE+6BE

Accepted for publication 1 December 1981 infectious, as it could be shortened by effective health education.

The aim of this study was to determine the mean incubation periods and duration of symptoms of gonorrhoea and NSU in men and to evaluate the effects of inexperience in those with a first episode of $\frac{}{3}$ urethritis (group A), of experience of urethritis in the past (group B), of "anxiety" (as implied by those who had attended previously of their own accord but without any detectable abnormality) (group C), and은 of being infected by known or unknown contacts.

\section{Patients and methods}

STUDY CRITERIA

To determine the mean incubation period and duration of symptoms in patients with gonorrhoea and NSU the clinic records for 1978 were studied retrospectively. The type of attendance (groups A-C) $\mathbb{D}$ and whether or not the sexual contact was known to the patient were noted.

The criteria for inclusion in the study were: (a) A record of the exact dates of infection and of the onset of symptoms. 
TABLE I Gonorrhoea and non-specific urethritis in men. Mean incubation periods and duration of symptoms by initial or previous attendance (days \pm SEM)

\begin{tabular}{|c|c|c|c|c|c|c|c|c|}
\hline \multirow[b]{2}{*}{ Attendance groups } & \multicolumn{2}{|c|}{ No (\%) of men with: } & \multicolumn{2}{|c|}{$\begin{array}{l}\text { Mean ( } \pm \text { SEM) incubation } \\
\text { periods (days): }\end{array}$} & \multicolumn{2}{|c|}{$\begin{array}{l}\text { Mean ( } \pm \text { SEM) duration } \\
\text { of symptoms (days): }\end{array}$} & \multicolumn{2}{|l|}{ Total periods } \\
\hline & Gonorrhoea & $N S U$ & Gonorrhoea* & NSUT & Gonorrhoea $\neq$ & $N S U \S$ & Gonorrhoea & NSU \\
\hline \multirow{2}{*}{$\begin{array}{c}\text { A: initial urethritis } \\
\text { B: repeated urethritis } \\
\text { C: no previous } \\
\text { abnormality }\end{array}$} & $\begin{array}{r}178(73 \cdot 6) \\
46(19 \cdot 0)\end{array}$ & $\begin{array}{rr}151 & (57 \cdot 2) \\
96 & (36 \cdot 4)\end{array}$ & $\begin{array}{l}6 \cdot 6 \pm 3 \cdot 8 \\
5 \cdot 4 \pm 3 \cdot 3\end{array}$ & $\begin{array}{l}8 \cdot 2 \pm 3 \cdot 8 \\
7 \cdot 4 \pm 4 \cdot 4\end{array}$ & $\begin{array}{l}3 \cdot 4 \pm 2 \cdot 4 \\
2 \cdot 5 \pm 1 \cdot 4\end{array}$ & $\begin{array}{l}4 \cdot 4 \pm 3 \cdot 6 \\
3 \cdot 4 \pm 3 \cdot 1\end{array}$ & $\begin{array}{r}10 \cdot 0 \\
7 \cdot 9\end{array}$ & $\begin{array}{l}12 \cdot 6 \\
10 \cdot 8\end{array}$ \\
\hline & $18 \quad(7 \cdot 4)$ & $17 \quad(6 \cdot 4)$ & $4 \cdot 4 \pm 2 \cdot 7$ & $5 \cdot 0 \pm 3 \cdot 3$ & $1 \cdot 6 \pm 1 \cdot 2$ & $3 \cdot 3 \pm 3 \cdot 1$ & $6 \cdot 0$ & $8 \cdot 3$ \\
\hline Totals & $242(100 \cdot 0)$ & $264(100 \cdot 0)$ & $6 \cdot 2 \pm 3 \cdot 8$ & $7 \cdot 7 \pm 4 \cdot 1$ & $3 \cdot 1 \pm 2 \cdot 3$ & $4 \cdot 0 \pm 3 \cdot 4$ & $9 \cdot 3$ & $11 \cdot 7$ \\
\hline
\end{tabular}

Statistical differences:

* A vs B, not significant; B vs $\mathrm{C}$, not significant; $\mathrm{A}$ vs $\mathrm{C}$, significant $(\mathrm{P}=0.002)$.

$+A$ vs $B$, not significant; $A$ vs $C$, significant $(\mathrm{P}<0.01)$; $\mathrm{B}$ vs $\mathrm{C}$, significant $(\mathrm{P}<0.01)$

$\neq A$ vs $B$ vs $C$, significant $(\mathrm{P}<0 \cdot 01)$

$\S$ A vs $\mathrm{B}$, significant; $(\mathrm{P}<0 \cdot 02)$

SEM = standard error of mean

(b) A past history of:

(i) No previous episode of urethritis but possible attendance with other conditions.

(ii) Previous attendance with urethritis of any sort.

(iii) No abnormality found on previous attendance for routine examination.

(c) The source of infection noted as known or unknown contact in the clinic records or the health adviser's contact cards.

STATISTICAL ANALYSIS

Statistical significances of differences were determined by the $\chi^{2}$ test and by Student's $t$ test (with Bessel's correction for small numbers) for differences of means.

\section{Results}

The criteria for inclusion in the study were fulfilled by 242 men with gonorrhoea, $51 \cdot 6 \%$ of the 1978 total, and by 264 with NSU (excluding those with post-gonococcal urethritis), $27 \cdot 4 \%$ of the total. Ninety per cent of those with gonorrhoea and $95 \%$ of those with NSU were born in the North-east of England.

The mean $( \pm$ SEM) incubation period for patients with gonorrhoea was $6 \cdot 2( \pm 3 \cdot 8)$ days and for those with NSU $7 \cdot 7( \pm 4 \cdot 1)$ days (table I). For those with gonorrhoea the only significant difference was between those with a first episode of urethritis (group A) and those who were "anxious" (group C) (table I). For patients with NSU the differences between groups $A$ and $C$ and between groups $B$ and $C$ were significant (table I).

The mean $( \pm$ SEM) duration of symptoms for patients with gonorrhoea was $3 \cdot 1( \pm 2 \cdot 3)$ days and that for those with NSU $4 \cdot 0( \pm 3 \cdot 4)$ days. For gonorrhoea the differences between all three groups were significant $(\mathrm{P}<0.01$ for all three). For NSU the only difference of possible significance was that between groups $\mathrm{A}$ and $\mathrm{B}(\mathrm{P}=0 \cdot 02)$ (table I).

\section{KNOWN AND UNKNOWN CONTACTS}

No significant difference in the mean incubation periods of gonorrhoea was found between those infected by known or unknown contacts (table II), both groups consisting of similar proportions of the three types of attendance $(0 \cdot 5>\mathrm{P}>0 \cdot 3)$. For NSU (also with similar proportions of the three types of attendance) $(P>0.5)$, however, the difference was significant $(P=0.001)$ and was due solely to the difference among those attending with a first episode of urethritis $(P<0.001)$. For both gonorrhoea and NSU the mean durations of symptoms of those infected by known contacts were significantly longer

TABLE II Gonorrhoea and non-specific urethritis in men. Mean ( \pm SEM) incubation periods and durations of symptoms by whether contact known or unknown (in days)

\begin{tabular}{|c|c|c|c|c|c|c|c|c|}
\hline \multirow[b]{2}{*}{ Contact } & \multicolumn{2}{|c|}{ No $(\%)$ of patients with: } & \multicolumn{2}{|c|}{$\begin{array}{l}\text { Mean ( } \pm \text { SEM) incubation } \\
\text { periods (days): }\end{array}$} & \multicolumn{2}{|c|}{$\begin{array}{l}\text { Mean }( \pm \text { SEM) duration } \\
\text { of symptoms (days): }\end{array}$} & \multicolumn{2}{|l|}{ Total periods } \\
\hline & Gonorrhoea & $N S U$ & Gonorrhoea & $N S U$ & Gonorrhoea & $N S U$ & Gonorrhoea & $N S U$ \\
\hline $\begin{array}{l}\text { Known } \\
\text { Unknown }\end{array}$ & $\begin{aligned} 78 & (32 \cdot 2) \\
164 & (67 \cdot 8)\end{aligned}$ & $\begin{array}{ll}106 & (40 \cdot 2) \\
158 & (59 \cdot 8)\end{array}$ & $\begin{array}{l}6 \cdot 9 \pm 4 \cdot 2 \\
5 \cdot 9 \pm 3 \cdot 6\end{array}$ & $\begin{array}{l}9 \cdot 0 \pm 4 \cdot 2 \\
6 \cdot 8 \pm 3 \cdot 7\end{array}$ & $\begin{array}{l}4 \cdot 9 \pm 2 \cdot 7 \\
2 \cdot 2 \pm 1 \cdot 1\end{array}$ & $\begin{array}{l}6 \cdot 0 \pm 4 \cdot 3 \\
2 \cdot 6 \pm 1 \cdot 7\end{array}$ & $\begin{array}{r}11 \cdot 8 \\
8 \cdot 1\end{array}$ & $\begin{array}{r}15 \cdot 0 \\
9 \cdot 4\end{array}$ \\
\hline Totals & $242(100 \cdot 0)$ & $264(100 \cdot 0)$ & $6 \cdot 2 \pm 3 \cdot 8$ & $7 \cdot 7 \pm 4 \cdot 1$ & $3 \cdot 1 \pm 2 \cdot 3$ & $4 \cdot 0 \pm 3 \cdot 4$ & $9 \cdot 3$ & $11 \cdot 7$ \\
\hline
\end{tabular}

SEM = standard error of mean 
$(P<0.001$ for both) than of those infected by unknown contacts.

For further analysis the three types of attendance were combined with knowledge or otherwise of the sexual contacts (table III). For both gonorrhoea and NSU the two longest mean incubation periods and durations of symptoms were associated with known contacts. In contrast the two shortest incubation periods were associated with group $C$ and the shortest duration of symptoms with unknown contacts of group C. Thus, no one factor influenced the incubation periods, but the durations of symptoms were predominantly determined by the type of contact; the three longest were associated with known contacts and the three shortest with unknown contacts, whereas within each of the three types of attendance the duration decreased from group $\mathbf{A}$ to group $\mathbf{B}$ to group $\mathbf{C}$.

\section{Discussion}

The mean incubation period ( $6 \cdot 2$ days) and duration of symptoms $(3 \cdot 1$ days) for patients with gonorrhoea were shorter than reported previously ${ }^{5}$ (7.9 and 4.5 days respectively). This may be due to the more rigid selection of patients in the present study. Both the mean incubation periods ( $7 \cdot 7$ days) and the duration of symptoms ( $4 \cdot 0$ days) for NSU were significantly longer than those for gonorrhoea $(P=0.001$ for both).

Previous experience of urethritis had only limited effect in shortening the interval between infection and attendance. Compared with those with 'a first episode of urethritis it had no effect on the incubation periods but did shorten the duration of symptoms. "Anxiety" was of greater benefit; possibly because of their increased awareness these patients noticed the symptoms of both conditions earlier, especially those with NSU. Its beneficial effect on the duration of symptoms was confined to those with gonorrhoea, possibly because the latter is a more painful condition than NSU.

The most important factor in determining the interval between infection and attendance, however, was whether or not the patient knew the contact. As might be expected in a specific infection knowledge of the contact did not prolong the incubation period of gonorrhoea for any of the three groups, but it had $\mathrm{c}$ a profound effect on the duration of symptoms. This $\vec{\circ}$ was also true of patients with NSU, but in addition the incubation period of those with a first episode of urethritis was significantly affected.

Thus the spectrum of initial infections of NSU may possibly have differed between the two groups, those acquired from strangers being the more virulent and $\omega$ having shorter incubation periods and duration of $\stackrel{\infty}{\oplus}$ symptoms than those acquired from friends. We 음 could not confirm this, because in 1978 we did not have a chlamydial culture service (Chlamydia tracho- $\subseteq$ matis being the most likely organism to be acquired from casual contacts). Such a service may not have been of help, however, as Oriel et $a l^{6}$ had noted that the mean incubation period of urethritis in patients $N$ harbouring chlamydia (16 days) was longer than in those who did not (12 days). Furthermore, most authors $^{7-9}$ have reported the mean duration of $\bar{\partial}$ symptoms of acute NSU to be about $30 \%$ longer when chlamydia had been isolated than when it had not. Only one author reported a marginally shorter mean duration of symptoms in the presence of chlamydia. ${ }^{10}$

Willcox ${ }^{11-13}$ found an association between the proportion of known contacts with initial episodes of urethritis and the length of the mean incubation

TABLE III Gonorrhoea and non-specific urethritis in men. Mean ( \pm SEM) incubation periods and durations of symptoms by type of attendance and knowledge of contact (in days)

\begin{tabular}{|c|c|c|c|c|c|c|c|c|c|c|}
\hline \multirow[b]{2}{*}{$\begin{array}{l}\text { Attendance } \\
\text { groups }\end{array}$} & \multirow[b]{2}{*}{ Contact } & \multicolumn{3}{|c|}{ No $(\%)$ of patients with: } & \multicolumn{2}{|c|}{$\begin{array}{l}\text { Mean }( \pm S E M) \text { incuba- } \\
\text { tion periods (days): }\end{array}$} & \multicolumn{2}{|c|}{$\begin{array}{l}\text { Mean ( } \pm \text { SEM) dura- } \\
\text { tion of symptoms (days): }\end{array}$} & \multicolumn{2}{|c|}{ Total periods } \\
\hline & & $\begin{array}{l}\text { Gonorr- } \\
\text { hoea }\end{array}$ & $N S U$ & & $\begin{array}{l}\text { Gonorr- } \\
\text { hoea }\end{array}$ & $N S U$ & $\begin{array}{l}\text { Gonorr- } \\
\text { hoea }\end{array}$ & $N S U$ & $\begin{array}{l}\text { Gonorr- } \\
\text { hoea }\end{array}$ & $N S U$ \\
\hline $\begin{array}{l}\text { A: initial } \\
\text { urethritis }\end{array}$ & Known & $59(24 \cdot 4)$ & 59 & $(22 \cdot 4)$ & $7 \cdot 1 \pm 4 \cdot 3$ & $10 \cdot 1 \pm 4 \cdot 1$ & $5 \cdot 3 \pm 2 \cdot 2$ & $6 \cdot 8 \pm 4 \cdot 5$ & $12 \cdot 4$ & $16 \cdot 9$ \\
\hline $\begin{array}{l}\text { A: initial } \\
\text { urethritis }\end{array}$ & Unknown & $119(49 \cdot 2)$ & 92 & $(34 \cdot 8)$ & $6 \cdot 4 \pm 3 \cdot 8$ & $7 \cdot 0 \pm 2 \cdot 9$ & $2 \cdot 4 \pm 1 \cdot 4$ & $2 \cdot 9 \pm 1 \cdot 6$ & $8 \cdot 8$ & $9 \cdot 9$ \\
\hline $\begin{array}{l}\text { B: repeated } \\
\text { urethritis } \\
\text { B. reneated }\end{array}$ & Known & $16 \quad(6 \cdot 6)$ & 38 & $(14 \cdot 4)$ & $6 \cdot 7 \pm 4 \cdot 1$ & $8 \cdot 4 \pm 3 \cdot 9$ & $3 \cdot 6 \pm 1 \cdot 5$ & $5 \cdot 3 \pm 3 \cdot 7$ & $10 \cdot 3$ & $13 \cdot 7$ \\
\hline $\begin{array}{l}\text { B: repeated } \\
\text { urethritis }\end{array}$ & Unknown & $30(12 \cdot 4)$ & 58 & $(22 \cdot 0)$ & $4 \cdot 8 \pm 2 \cdot 6$ & $6 \cdot 7 \pm 4 \cdot 7$ & $1 \cdot 9 \pm 1 \cdot 0$ & $2 \cdot 2 \pm 1 \cdot 6$ & $6 \cdot 7$ & $8 \cdot 9$ \\
\hline $\begin{array}{l}\text { C: no previous } \\
\text { abnormality } \\
\text { C: no previous }\end{array}$ & Known & $3 \quad(1 \cdot 2)$ & 9 & $(3 \cdot 4)$ & $3 \cdot 3 \pm 0 \cdot 8$ & $4 \cdot 9 \pm 3 \cdot 1$ & $3 \cdot 0 \pm 0 \cdot 0$ & $4 \cdot 3 \pm 3 \cdot 9$ & $6 \cdot 3$ & $9 \cdot 2$ \\
\hline abnormality & Unknown & $15 \quad(6 \cdot 2)$ & 8 & $(3 \cdot 0)$ & $4 \cdot 6 \pm 2 \cdot 9$ & $5 \cdot 3 \pm 3 \cdot 4$ & $1 \cdot 3 \pm 0 \cdot 7$ & $2 \cdot 1 \pm 1 \cdot 1$ & $5 \cdot 9$ & $7 \cdot 4$ \\
\hline
\end{tabular}

SEM = standard error of mean 
periods, as in this study. The overall longer mean duration of symptoms (3.9 days) could have been associated with the higher proportion of known contacts $(49 \%)$ compared with the $32 \%$ reported here.

In one report on patients with $\mathrm{NSU}^{14}$ the mean incubation period was longer than 9.5 days and the duration of symptoms more than $9 \cdot 0$ days compared with $7 \cdot 7$ and $4 \cdot 0$ days respectively in this study. A similar proportion (57\%) had an initial episode of urethritis, but $72 \%$ had known contacts compared with only $40 \%$ in this study; this may explain the differences in the inrubation periods and durations of symptoms.

While those with initial episodes of urethritis and known contacts have been identified as groups at special risk of having prolonged symptoms, the benefit of having a repeat episode of urethritis was minimal. Anxious patients and those with unknown contacts were rarely at risk, and, when combined, the maximum duration of symptoms for gonorrhoea was three days and for NSU four days. Symptoms were prolonged (eight days or more) in five $(2 \cdot 1 \%)$ of those with gonorrhoea and in $21(8.0 \%)$ of those with NSU; all were associated with known contacts. Of those with gonorrhoea, three had repeat episodes of urethritis and two first episodes. Among those with NSU 16 had first episodes of urethritis, four repeat episodes, and one no abnormality detected on previous attendance. Conversely, extremely short durations of symptoms were all associated with unknown contacts. Six $(2 \cdot 5 \%)$ men with gonorrhoea, but none with NSU, attended within a day of noticing symptoms, five having no abnormality on previous attendance and one a repeat episode of urethritis.

Patients, therefore, need to be more generally aware that known contacts may be a source of infection, even when the relationship is stable, and that the period of reconciliation after separation is especially dangerous. The public also need to be educated away from the attitude of "it can't happen to me." In the clinics all patients, with or without urethritis, should be educated to attend for routine examination after contact with strangers, or as soon as symptoms develop, but not to indulge in persistent self-examination. Finally, clinicians should always examine carefully even the most persistent of "neurotic" patients, because they may become infected eventually.

\section{References}

1. King A, Nicol CS, Rodin P. Venereal Diseases, 4th ed London: Baillière and Tindall, 1980: 199.

2. Catterall RD. A Short Textbook of Venereology. 2nd ed. London: English Universities Press, 1974:16.

3. Morton RS. Gonorrhoea. London: WB Saunders, 1977: 70.

4. Robertson DHH, McMillan A, Young H. Clinical Practice in Sexually Transmitted Diseases. Tunbridge Wells: Pittman Medical, 1980: 167

5. Schofield CBS. Sexually Transmitted Diseases. 3rd ed Edinburgh: Churchill Livingstone, $\cdot 1979: 135$.

6. Oriel JD, Reeve P, Powis P, Miller A, Nicol CS. Isolation of chlamydia from patients with non-specific genital infection. Br J Vener Dis 1972; 48:429-36.

7. Alani MD, Darougar S, MacD Burns DC, Thin RN, Dunn H. Isolation of Chlamydia trachomatis from the male urethra. $\mathrm{Br}$ $J$ Vener Dis 1977;53: 88-92.

8. Perroad HM, Miedzybrodzka K. Chlamydial infection of the urethra in men. Br J Vener Dis 1978;54:45-9.

9. Terho P. Chlamydia trachomatis in non-specific urethritis. $\mathrm{Br}$ $J$ Vener Dis 1978;54:251-6.

10. Ghadirian FD, Robson HG. Chlamydia trachomatis genital infections. Br J Vener Dis 1979; 55:415-8.

11. Willcox RR. Effective treatment of gonorrhoea in London with two oral doses of amoxycillin. Br J Vener Dis 1974 50: $120-4$.

12. Willcox RR. Spectinomycin in the treatment of gonorrhoea in males. Br J Vener Dis 1974; 50:294-7.

13. Willcox RR. Single oral dose of $1.5 \mathrm{~g}$ talampicillin in the treatment of gonorrhoea. Br J Vener Dis 1976;52:184-6.

14. Willcox RR, Sparrow RW, Fazluddin CM. Minocycline in the treatment of non-gonococcal urethritis. Br J Vener Dis 1975;51:206-9. 